\title{
Deep Brain Stimulation for Parkinson's Disease
}

\author{
Patricia Limousin and Irene Martinez-Torres \\ Unit of Functional Neurosurgery, Sobell Department of Motor Neuroscience and Movement Disorders, Institute of Neurology, \\ University College London, London, England, United Kingdom
}

\begin{abstract}
Summary: The surgical treatment of Parkinson's disease has been through a revival phase over the last 20 years with the development of deep brain stimulation (DBS). Thalamic DBS was developed first and has proven to be a very effective treatment for tremor. The limitation is the lack of effect on other symptoms. Other targets were therefore investigated, and the procedure was applied to the subthalamic nucleus (STN) and the internal globus pallidus (GPi). STN stimulation can improve a wide range of symptoms and is currently the preferred target for many patients. Nevertheless, the morbidity
\end{abstract}

seems higher than with other targets, and the selection criteria have to be quite strict. When STN DBS is not advised, thalamic DBS remains an option for patients with severe tremor, and GPi stimulation for those with severe dyskinesias. DBS remains a symptomatic treatment for a limited number of patients; it does not seem to alter the disease progression, and many patients are not suitable. There is, therefore, the need for further research into other targets and other approaches. Key Words: Parkinson's disease, deep brain stimulation, subthalamic nucleus, globus pallidus pars interna, thalamus.

\section{INTRODUCTION}

The first line of treatment for Parkinson's disease remains dopaminergic medications. Deep brain stimulation (DBS) can provide additional help for selected patients whose symptoms are not controlled sufficiently by medication. DBS has progressively replaced brain lesioning, such as thalamotomies and pallidotomies, over the last 20 years. After a few earlier reports on the use of DBS, ${ }^{1,2}$ the first target in the modern era of DBS was the ventro-intermediate nucleus (Vim) of the thalamus in $1987 .{ }^{3}$ Thalamic DBS was initially performed contralateral to thalamotomies to try to reduce the morbidity of bilateral procedures, particularly on speech and balance. ${ }^{1}$ In view of its efficacy on tremor, adaptability, and low morbidity, thalamic DBS was progressively performed bilaterally, ${ }^{4}$ and the positive effect on tremor was confirmed. Thalamic DBS provided limited effect on other symptoms, however, such as limb bradykinesia or rigidity, and no favorable effect on gait and balance.

The limits to the effectiveness of thalamic DBS led to the application of this procedure to new targets, the internal globus pallidus (GPi) and the subthalamic nucleus (STN), in parallel in $1993 .^{5-7}$ The application of DBS to the GPi was based on the noted similarities of the effect

Address correspondence and reprint requests to: Patricia Limousin, M.D., Institute of Neurology, Box 146, Queen Square, London WC1N3BG, UK. E-mail: p.limousin@ion.ucl.ac.uk. of a lesion and high-frequency stimulation to the thalamus and the knowledge on the effect of pallidotomies. ${ }^{8}$ The application to the STN was based on basic research work on the STN in 1-methyl-4-phenyl-1,2,3,6-tetrahydropyridine (MPTP)-treated monkeys; the animals displayed an excess of activity in the STN and improvement of parkinsonian symptoms with lesions or high-frequency stimulation of the STN. ${ }^{9-11}$

STN has progressively become the preferred target for DBS for Parkinson's disease, because it has been found to have a positive effect on a wide range of symptoms. Nevertheless, both thalamic and GPi DBS have their place and should not be neglected. It has also become clear that the existing targets are not suitable for every parkinsonian patient; in particular, dopa-refractory symptoms are not improved. There remains a need for further research to identify new target areas to improve symptoms refractory with the existing targets or to develop different approaches to parkinsonian treatment-in particular, gene or cell therapy.

Here we review the benefits and side effects of the three DBS procedures, define criteria for patient selection, and discuss the future of the surgical treatment of Parkinson's disease.

\section{SURGICAL PROCEDURE}

In most surgical centers, the electrodes are implanted under local anesthesia for thalamic and STN DBS, 
to allow intraoperative stimulation and assessment of symptoms and side effects and allow microrecordings if desired. Although STN implantation is also possible under general anesthesia (particularly in the most severe cases), a comparative study has shown only a slight difference in the benefits between implants under local or general anesthesia. ${ }^{12}$ GPi implantations are often performed under general anesthesia, because the acute effect is not as clear with this target.

The target is usually located using a combination of methods, which vary according to the surgical center. Stereotaxic MRI is used in most centers. The STN and GPi are visible on MRI pictures ${ }^{13}$ (Fig. 1), but the thalamic nuclei are not visible on standard MRI machines and identifying the target in the thalamus requires indirect targeting using atlas coordinates. In surgery, microrecordings are used in many centers to localize neuronal activity typical of a nucleus, ${ }^{14,15}$ although the safety of this process has been questioned. ${ }^{16}$ Local field potentials have also been suggested to help in the identification of the STN, although their role is not fully established. ${ }^{17}$ Acute electrical stimulation and assessment of the clinical effect during surgery is particularly useful for the thalamus and the STN.

During thalamic implant, the benefit is assessed on tremor and the main side effects are dysarthria, sensory effects, muscle contractions, and cerebellar signs. During STN implant, improvement of limb rigidity, tremor and bradykinesia is observed as well as the inducement of dyskinesias. In the STN area, side effects of stimulation can be highly variable and include, for example, sensory effects, eye movements, vegetative symptoms, dysarthria, and muscle contractions.

The electrodes most frequently implanted at present are quadripolar electrodes with 1.5 -mm-long contacts, separated with a $0.5-\mathrm{mm}$ gap for the STN and GPi (model 3389; Medtronic, Minneapolis, MN) and a 1.5-mm gap for the thalamus and GPi (model 3387, Medtronic). The connectors and the battery are implanted under general anesthesia in the same sessions, or a few days later. The battery currently available is either dual channel (Kinetra, Medtronic) or single channel (Soletra, Medtronic). A larger range of equipment is expected to become available in the near future.

The main risks of surgery for all target areas are intracranial bleeding, reported in $1 \%$ to $4 \%$ of patients, and infection, reported in $2 \%$ to $18 \%$ of patients, in different studies. ${ }^{18-28}$ In rare cases, seizure is observed. Hardware problems such as lead fracture or battery failure have also been reported, ${ }^{19,20,26}$ and are estimated at $4.3 \%$ per electrode. ${ }^{29}$ Side effects are reviewed in the following sections for each target individually.

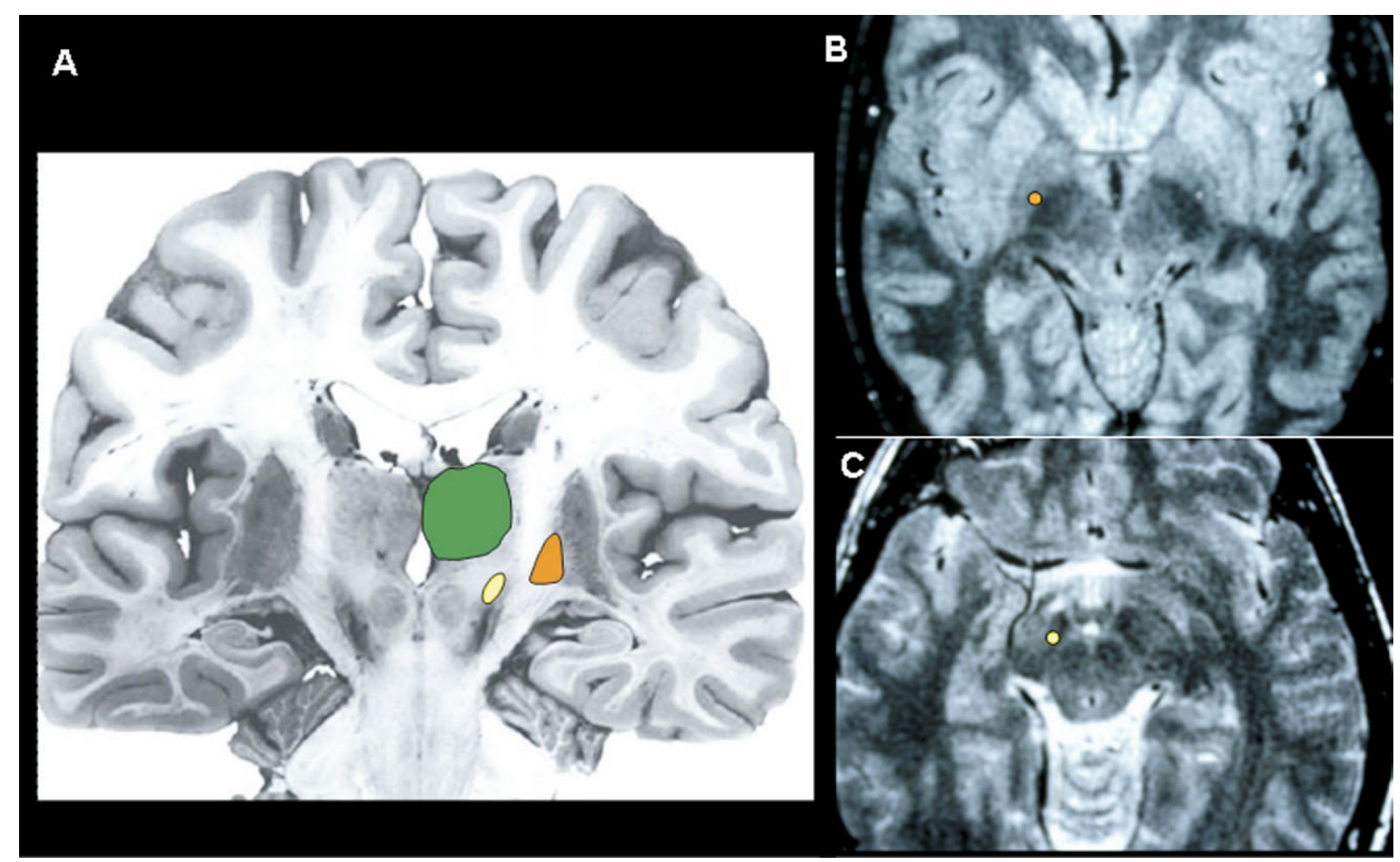

FIG. 1. Targets for deep brain stimulation in Parkinson's disease. Coronal view of the three targets (A): the subthalamic nucleus is represented in yellow, the globus pallidus in orange, and the thalamus in green. Axial MRI images show the globus pallidus (B) and the subthalamic nucleus (C). 


\section{POSTOPERATIVE FOLLOW-UP}

The adjustment of electrical parameters can begin as soon as the patient is well enough and ready to collaborate. Symptoms can be improved for a short time after surgery by the physical implantation of the electrodes; however, this implant effect usually wears off after a few weeks.

The first step of the adjustment process is to determine which of the four contacts is the most effective for each side. The electrical parameters used are relatively similar for the three targets. The frequency must be greater than $100 \mathrm{~Hz}$, and $130 \mathrm{~Hz}$ is the most often used. The range of voltage is usually between $2 \mathrm{~V}$ and $4 \mathrm{~V}$. The pulse width is usually $60 \mu \mathrm{s}$, occasionally $90 \mu \mathrm{s}$, and tends to be higher in GPi DBS. Monopolar stimulation is generally preferred, unless side effects limit the increase in voltage. For thalamic DBS, the voltage can be set immediately to an effective level. For STN DBS, the voltage has to be progressively increased in parallel with adjustment of medications, otherwise there is a risk of worsening dyskinesias or inducing neuropsychiatric side effects. With GPi DBS, it can be more difficult to assess a direct effect on symptoms of change in electrical parameters.

Patients implanted with DBS need long-term follow-up by a specialist team. Stimulation parameters have to be adjusted from time to time, as well as medication. The existing batteries have to be replaced approximately every 4 to 7 years, although new generations of batteries are likely to last longer and some models will be rechargeable.

Infections can also occur some time after surgery, and patients should take preventive antibiotics in appropriate circumstances. Some medical devices, such as monopolar coagulation, should not be used in DBS patients; diathermy is strictly forbidden. Cranial MRI can be done only under very restricted conditions of energy delivery and using a receiver-transmitter head coil.

\section{THALAMIC DBS}

\section{Beneficial effect}

The main effect of thalamic stimulation is to improve contralateral limb tremor. ${ }^{1,4,30-35}$ A small effect on limb bradykinesia and rigidity can be observed, but this could be related to the improvement in tremor making movement easier. ${ }^{32}$ Gait and balance do not improve after thalamic DBS. ${ }^{32,35,36}$ Improvement in daily living activities and quality of life has been reported..$^{32,34,37}$ To provide additive beneficial effect against tremor (as well as other symptoms), drug dosage is not usually reduced after thalamic DBS. ${ }^{32}$ The benefit on tremor can be maintained for more than 5 years. ${ }^{33,35}$ A multicenter study with 6 years of follow-up for 38 parkinsonian patients confirmed the persistence of the benefit on tremor, but a worsening of axial scores and a loss of improvement in activities of daily living. ${ }^{38}$

Some patients develop other symptoms that have in the long term become more troublesome than the tremor. ${ }^{39}$ Some of these patients have later undergone DBS in the STN ${ }^{40}$ although today, in the majority of those patients, the STN target would have been chosen first. Nevertheless, thalamic DBS remains a useful treatment for patients with severe tremor who are considered not suitable for STN DBS.

\section{Target-related side effects}

Dysarthria is reported in up to $20 \%$ of patients after bilateral thalamic DBS. ${ }^{32,35}$ Balance can deteriorate in $3 \%$ to $10 \%$ of patients, particularly after bilateral procedures. ${ }^{32,35}$ In some patients, those side effects are related to the amplitude of stimulation and are therefore adjustable. This is not always the case, however, and patients with balance difficulty and marked dysarthria before surgery should be considered carefully for the risk of deterioration. Disease progression also seems to play a role in the incidence of dysarthria. ${ }^{38}$ Paresthesias are frequent and usually transient when the stimulation is turned on. Thalamic stimulation does not have any major effect on cognitive functions, although only a few studies have focused on this matter. ${ }^{41,42}$

In the long term, some patients can develop some tolerance to the effect of the stimulation and experience rebound of tremor when stimulation is stopped. ${ }^{43}$ To try to prevent this development, patients are usually advised to stop the stimulation at night or when it is not needed.

\section{PALLIDAL DBS}

\section{Beneficial effect}

The most constant beneficial effect of GPi DBS is against dyskinesias, ranging between $50 \%$ and $76 \%$ improvement on dyskinesia scales (Table 1). ${ }^{18-21,43-47}$ This effect is maintained over time for at least 4 or 5 years. ${ }^{24,46}$ It is a direct effect of the stimulation, because none of the studies show a significant reduction of the levodopa equivalent dosage (Table 1). The on-drug motor score usually remains unchanged. ${ }^{19,24,44,45,47}$ The effect of GPi DBS on the duration and severity of off symptoms is variable, with Unified Parkinson's Disease Rating Scale (UPDRS) III improvement ranging from $26 \%$ to $56 \%$ (Table 1). Some studies have reported a loss of the benefit against off symptoms over time, ${ }^{24,46}$ and a reduction of duration of off-phases has been reported in some studies ${ }^{19,20,44,45}$ (Table 1). The type of off-drug symptoms improved also varies between studies, some reporting an effect on limb symptoms only, others reporting an additional effect on axial symptoms. ${ }^{48}$ The complexity of the GPi might explain this variability of effect. ${ }^{49,50}$ Some studies have reported an improvement 
Table 1. Selected Studies of Deep Brain Stimulation of the GPi in Parkinson's Disease

\begin{tabular}{|c|c|c|c|c|c|c|c|}
\hline Reference & $\begin{array}{l}\text { Type of } \\
\text { Study }\end{array}$ & $N(\mathrm{Bi})$ & $\begin{array}{c}\text { Follow-up, } \\
\text { mo }\end{array}$ & $\begin{array}{l}\% \text { Change in } \\
\text { UPDRS-III,* } \\
\text { Off Med }\end{array}$ & $\begin{array}{l}\% \text { Change in } \\
\text { UPDRS-III,* } \\
\text { On Med }\end{array}$ & $\begin{array}{c}\% \text { Reduction, } \\
\operatorname{LID}^{\dagger}\end{array}$ & $\begin{array}{l}\text { \% Reduction, } \\
\text { Time Off }\end{array}$ \\
\hline $\begin{array}{l}\text { Rodrigues et al. }{ }^{48} \\
\text { (2007) }\end{array}$ & Prosp & $20(11)$ & 35 & $-46^{\S}$ & N.S. ${ }^{\S}$ & $76^{\S}$ & NA \\
\hline $\begin{array}{l}\text { Volkman et al. }{ }^{24} \\
(2004)\end{array}$ & Prosp, open & $11(11)$ & $12 / 36 / 60$ & $-56 /-46 / \mathrm{N} . S$ & $-50 /-55 /$ N.S. & $58 / 63 / 64$ & $78 / 78 / 83^{\text {II }}$ \\
\hline $\begin{array}{l}\text { Durif et al. } \\
\text { (2002) }\end{array}$ & Prosp & $6(5)$ & $12 / 24 / 36$ & $-26 /-38 /-32$ & N.S./N.S./N.S. & N.S./N.S./50 & 25/40/N.S. \\
\hline $\begin{array}{l}\text { Kumar et al. }{ }^{19} \\
(2000)\end{array}$ & Prosp, multi & $22(17)$ & 6 & -31 & N.S. & 68 & 71.79 \\
\hline $\begin{array}{l}\text { Lyons et al. }{ }^{20} \\
\text { (2002) }\end{array}$ & Prosp & $9(6)$ & 48.5 & -37 & -39 & 64.28 & 18.2 \\
\hline $\begin{array}{l}\text { Loher et al. }^{21} \\
\text { (2002) }\end{array}$ & Prosp & $16(10)$ & 12 & $-41^{\S}$ & $-33^{\S}$ & $71^{\S}$ & NA \\
\hline $\begin{array}{l}\text { Ghika et al. }{ }^{44} \\
\text { (1998) }\end{array}$ & Prosp & 6 & 24 & -50 & N.S. & 65 & 50 \\
\hline
\end{tabular}

Studies were selected on the basis of a larger number of patients and longer duration of follow-up.

$\mathrm{Bi}=$ bilateral; $\mathrm{LID}=$ levodopa-induced dyskinesia; med = medication; multi = multicenter; $\mathrm{NA}=$ not available; $\mathrm{NC}=$ no change; $\mathrm{N} . \mathrm{S} .=$ not significant; open = open-label; prosp = prospective; UPDRS = Unified Parkinson's Disease Rating Scale.

*In the on-stimulation condition, with respect to preoperative scores. Negative values (minus sign) indicate a reduction in the scores and therefore an improvement. ${ }^{\dagger}$ Scales used to score dyskinesia differed across studies. ${ }^{\ddagger}$ Scored using the UPDRS-IV items $36-39 .{ }^{\S}$ Data shown for bilateral pallidal stimulation only. ${ }^{\text {IT }}$ Percentage of patients with less than $25 \%$ of the waking day in off time.

in quality of life, largely related to the improvement in dyskinesias. ${ }^{51}$

\section{Target-related side effects}

GPi DBS tends to have a low rate of morbidity in most studies. $^{46,47,52}$ The side effects related to the voltage include paresthesias, muscle contraction, and visual flash, in particular from the most ventral contacts. Stimulation of the most ventral part of the GPi area may also worsen akinesia, both off and on medication. ${ }^{49,50}$ Dysarthria, weight gain, eyelid-opening apraxia, confusion, and cognitive decline have also been described. ${ }^{18-20,44,47}$ Psychiatric problems are rare. Stimulation parameters tend to be higher with GPi DBS than with STN DBS and so the battery life can be shorter. ${ }^{53}$

\section{STN DBS}

\section{Beneficial effect}

STN DBS is an effective treatment for selected patients with Parkinson's disease. Off motor symptoms can improve dramatically; the percentage of improvement in most studies is between $40 \%$ and $60 \%$ (Table 2). ${ }^{22,23,26-28,54-56}$ Limb bradykinesia, rigidity, and tremor usually improve, as do some axial symptoms. Axial symptoms-in particular gait difficulty, including balance and freezingimprove with STN stimulation if they are levodopa sensitive. Levodopa-induced dyskinesias also improve over time, with usually a greater than $50 \%$ reduction on dyskinesia scales (Table 2). ${ }^{22,23,26-28,54-57}$ This improvement is probably related to a reduction in drug dosage. Off dystonia can improve as well. ${ }^{58}$ The effect on speech can be variable and intelligibility can deteriorate. ${ }^{59}$ Medications have typically been reduced after STN DBS by $30 \%$ to $50 \%$ (Table 2). Nevertheless, reducing medications excessively could increase the risk of developing apathy or depression. ${ }^{60}$

All the studies with long-term follow-up have shown some decline of benefit over time..$^{22,26,27,47,55}$ Axial symptoms such as freezing, postural stability, and speech deteriorate both off and on medications. A number of patients also developed dementia in the follow-up period. $^{22,26,28}$ This progression of symptoms and the appearance of dementia years after surgery is compatible with disease progression, but in the absence of a longterm control group it is difficult to be sure whether the surgery has affected disease progression or not. A study suggests that the incidence of dementia up to 3 years after STN DBS is similar to that reported in medically treated patients, with the same risk factors of older age, hallucinations, and poorer executive functions. ${ }^{61}$ Animal studies have suggested a possible neuroprotective role of STN DBS, ${ }^{62}$ but so far this has not been established in humans.

Quality of life improves after STN DBS, ${ }^{56,63-67}$ and this improvement correlates with motor benefit. ${ }^{65}$ In support of this finding, the physical markers for quality of life are reported to improve significantly, but other aspects such as mental, emotional well-being, social support, cognition, and communication show no improvement. ${ }^{66,67}$ The improvement in quality of life is maintained over time. ${ }^{64,65}$ The caregiver's quality of life can also improve. ${ }^{64}$ Nevertheless, two studies have 
Table 2. Selected Studies of Deep Brain Stimulation of the STN in Parkinson's Disease

\begin{tabular}{|c|c|c|c|c|c|c|c|c|}
\hline Reference & Type of Study & $N$ & $\begin{array}{l}\text { Follow-up, } \\
\text { mo }\end{array}$ & $\begin{array}{l}\text { \% Change in UPDRS- } \\
\text { III,* Off Med }\end{array}$ & $\begin{array}{c}\text { \% Change in UPDRS- } \\
\text { III,* On Med }\end{array}$ & $\begin{array}{l}\% \text { Reduction, } \\
\text { LID }^{\dagger}\end{array}$ & $\begin{array}{l}\% \text { Reduction, } \\
\text { Time Off }\end{array}$ & $\begin{array}{l}\text { \% Reduction, } \\
\text { LEDD }\end{array}$ \\
\hline $\begin{array}{l}\text { Wider et al. }{ }^{28} \\
(2007)\end{array}$ & Prosp & 37 & $6 / 12 / 60$ & $-44 /-47 / 26$ & $\mathrm{NA} / \mathrm{NA} /+26$ & $85 / 83 / 85$ & $87 / 76 / 84$ & $83 / 67 / 57$ \\
\hline $\begin{array}{l}\text { Deuschl et al. } \\
\text { (2006) }\end{array}$ & R (STN/MT) & $156(78 / 78)$ & 6 & $-41 / \mathrm{NC}$ & $-22 / \mathrm{NC}$ & $50 / 4$ & $4.2 \mathrm{~h} / \mathrm{NC}$ & $50 / 8$ \\
\hline $\begin{array}{l}\text { Krack et al. }^{22} \\
\text { (2003) }\end{array}$ & Prosp & 49 & $12 / 36 / 60$ & $-66 /-59 /-54$ & $-20 /+7 /+47$ & $63 / 68 / 58$ & NA/NA/NA & $59 / 63 / 63$ \\
\hline $\begin{array}{l}\text { Østergaard et al. }{ }^{27} \\
(2006)\end{array}$ & Prosp & 22 & 48 & -55 & N.S. ${ }^{\S}$ & 90 & 67 & 29 \\
\hline $\begin{array}{l}\text { Schüpbach et al. } \\
\text { (2005) }\end{array}$ & Prosp & 30 & $6 / 24 / 60$ & $-59 /-69 /-54$ & $-36 /-43 / \mathrm{NC}$ & NA/NA/67 & $81 / 85 / 73$ & $64 / 63 / 58$ \\
\hline $\begin{array}{l}\text { Rodriguez-Oroz } \\
\text { et al. }{ }^{55}(2004)\end{array}$ & $\begin{array}{l}\text { Prosp, double- } \\
\text { blind, cross-over }\end{array}$ & 10 & 48 & -62 & NA & 53 & NA & 50 \\
\hline $\begin{array}{l}\text { Krause et al. } \\
\quad(2004)\end{array}$ & Prosp & 24 & 30 & -38 & NA & 70 & 16 & 30 \\
\hline $\begin{array}{l}\text { Herzog et al. } \\
\text { (2003) }\end{array}$ & Prosp & 20 & 24 & -57 & -35 & 85 & NA & 67 \\
\hline $\begin{array}{l}\text { Kleiner-Fisman } \\
\text { et al. }{ }^{57}(2003)\end{array}$ & Prosp & 25 & 24 & -39 & N.S. & 66 & 58 & 42 \\
\hline
\end{tabular}

Studies were selected on the basis of a larger number of patients and longer duration of follow-up.

LEDD = levodopa equivalent daily dose; LID = levodopa-induced dyskinesia; med = medication; $\mathrm{MT}=$ medical treatment; NA = not available; NC = no change; N.S. = not significant; Prosp = prospective; $\mathrm{R}=$ randomized; STN = subthalamic nucleus; UPDRS = Unified Parkinson's Disease Rating Scale.

*Scores in the on-stimulation condition, with respect to preoperative scores. Negative values (minus sign) indicate a reduction in the scores and therefore an improvement; positive values (plus sign) indicate an increase and therefore worsening in the UPDRS-III scores. ${ }^{\dagger}$ Scales used to score dyskinesia differed across studies. ${ }^{*}$ Scales used to score time off differed across studies. ${ }^{8}$ Not significant compared with baseline (before surgery); worsening compared with 1 year after surgery. 
shown quality of life does not improve as much in older patients. ${ }^{68,69}$ A study has pointed out the maladjustment of some patients to the after-DBS life seems to be of multifactorial origin and warrants further study. ${ }^{70}$

Some improvement in nonmotor symptoms has been reported, such as in constipation, ${ }^{71}$ sleep,,${ }^{71,72}$ sensory complaints, ${ }^{72,73}$ and some bladder complaints, ${ }^{74}$ as well as urodynamic parameters. ${ }^{75}$

A randomized study has confirmed the superiority of STN DBS to medical management at 6 months followup. ${ }^{56}$ Some studies have shown that STN DBS is a costeffective treatment of advanced Parkinson's disease. ${ }^{76,77}$

\section{Target-related side effects}

Side effects are not infrequent after STN DBS; they include dysarthria, neuropsychiatric problems (such as mood change, confusion, and apathy), eyelid opening apraxia, weight gain, and stimulation-induced dyskinesia. The confusion, weight gain, and stimulation-induced dyskinesia tend to be limited to the first postoperative period.

Akinesia can be worsened in particular if the electrodes are placed too deep. Some side effects including neuropsychiatric problems ranging from depression or apathy to mania, and these can occur some time after surgery. Patients should be monitored for neuropsychiatric problems. Some of the problems can be related to a reduction in drug dosage (depression and apathy, in particular $^{60}$ ) or can be induced by the stimulation (mania, for example ${ }^{78}$ ); both factors may apply.

Many studies have looked at changes in cognitive functions after surgery. The most constant finding is a decline in verbal fluency. ${ }^{79,80} \mathrm{~A}$ meta-analysis ${ }^{81}$ has shown a significant, albeit small, decline in executive functions and verbal learning and memory and has confirmed a moderate decline in semantic and phonemic verbal fluency. In the majority of patients, those changes do not have a clinically meaningful effect on daily living activities. ${ }^{80}$ The challenge is to identify patients with cognitive problems before surgery, because they are at risk of a more significant decline afterwards. ${ }^{82}$

\section{COMPARISON OF GPI AND STN DBS}

Fifteen years after the start of application of DBS to the STN and GPi, there is still a scarcity of comparative data between the two targets. STN was quickly preferred to GPi, especially because of the perceived marked and more reliable effect on off-symptoms (in particular, gait and balance). Some of the early studies of GPi DBS had also raised the possibility of some loss of benefit over time. ${ }^{24}$ Therefore, a larger number of studies have been done on STN, and with a larger number of patients, than with GPi DBS.
A number of studies, often in small populations of patients, have included a group of patients with implantation in the GPi and another group with implantation in the STN (Table 3). ${ }^{46,47,53,83-85}$ The only such randomized and blinded study, ${ }^{52}$ in 10 patients with STN implants and 10 patients with GPi implants, with follow-up at 12 months, has shown little difference between the groups: a $48 \%$ improvement of the UPDRS III in the STN group and 39\% improvement in the GPi group. Dyskinesias were reduced by $62 \%$ with STN DBS and $89 \%$ with GPi DBS. The reduction in medication was greater in the STN group.

These results are very similar to those of an open, nonrandomized, multicenter study that included a larger number of patients: 91 patients with STN DBS and 36 with GPi DBS. ${ }^{46}$ A longer follow-up of that study (over 3-4 years) has shown similar improvement. ${ }^{47}$ Several smaller, open, single-center studies including both STN and GPi groups have confirmed the efficacy of both targets against off symptoms and dyskinesias. ${ }^{18,84,85}$ Nevertheless, bradykinesia and, to a lesser degree, axial symptoms are better improved with STN.

The mechanism of action of STN and GPi DBS on dyskinesias appears to be different. GPi DBS seems to have a direct effect against dyskinesias, even if medications are not reduced. With STN DBS, the reduction in medications seems largely responsible for the reduction in dyskinesias. The drug dosage is rarely reduced after GPi DBS. The more stable drug dosage in the GPi population could contribute to the lower psychiatric morbidity. Most studies report a lower rate of side effects (in particular, psychiatric side effects) with GPi DBS ${ }^{46,47,52}$. There is still a place for GPi DBS, especially in the population of patients considered at risk of psychiatric problems after STN DBS. A randomized study has also demonstrated the superiority of STN DBS relative to pallidotomy. ${ }^{86}$

\section{PATIENT SELECTION}

The decision whether to operate upon a patient is primarily based on a risk versus benefit assessment. The most disabling symptoms that at times limit the patient's activity and quality of life should be identified, to assess if they are likely to respond to surgery. It is important to assess whether these symptoms are dopa-sensitive or dopa-induced, because these are as a general rule more likely to respond to surgery. ${ }^{87} \mathrm{~A}$ dopa challenge helps in assessing these aspects. For STN DBS it is particularly important to assess whether gait difficulty (in particular, freezing and balance) are dopa-sensitive, because these improve only if dopa-sensitive. The place of STN DBS in patients with dopamine dysregulation syndrome or side effects from dopaminergic medication is not fully 
Table 3. Studies Comparing Deep Brain Stimulation of the STN and GPi in Parkinson's Disease

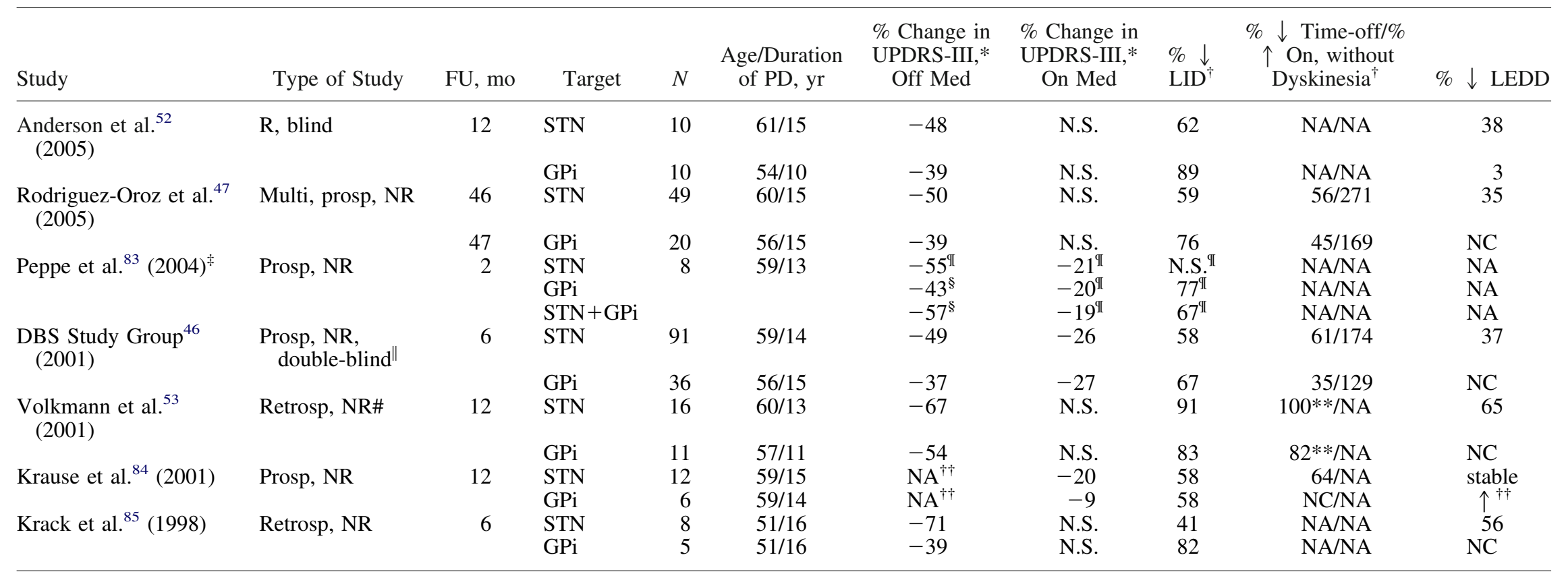

$\mathrm{FU}=$ follow-up $\mathrm{GPi}=$ internal globus pallidus; $\mathrm{LEDD}=$ levodopa equivalent daily dose LID $=$ levodopa-induced dyskinesia; multi $=$ multicenter; $\mathrm{NA}=$ not available NC $=$ no change $\mathrm{NR}=$ nonrandomized; N.S. $=$ not significant; Off-med $=$ off medication; On-med $=$ on medication; prosp $=$ prospective; stim $=$ stimulation; $\mathrm{R}=$ randomized; retrosp $=$ retrospective; $\mathrm{STN}=$ subthalamic nucleus; UPDRS = Unified Parkinson's Disease Rating Scale; $\downarrow=$ decrease; $\uparrow=$ increase.

*Scores in the on-stimulation condition, with respect to preoperative scores. Negative values (minus sign) indicate a reduction in the scores and therefore an improvement. ${ }^{\dagger}$ Scales used to score dyskinesia differed across studies. ${ }^{*}$ Implantation into both GPi and STN in all the patients. ${ }^{\S}$ Compared with the condition off-medication and off-stimulation. ${ }^{\text {IT }}$ Compared with the condition on-medication and off-stimulation. "Double-blind with respect to site of stimulation. ${ }^{\#}$ Both groups in series, not in parallel. **Percentage of patients reporting a reduction in the off periods. ${ }^{\dagger}$ No numeric data available. 
Table 4. General Criteria for Deep Brain Stimulation for Parkinson's Disease

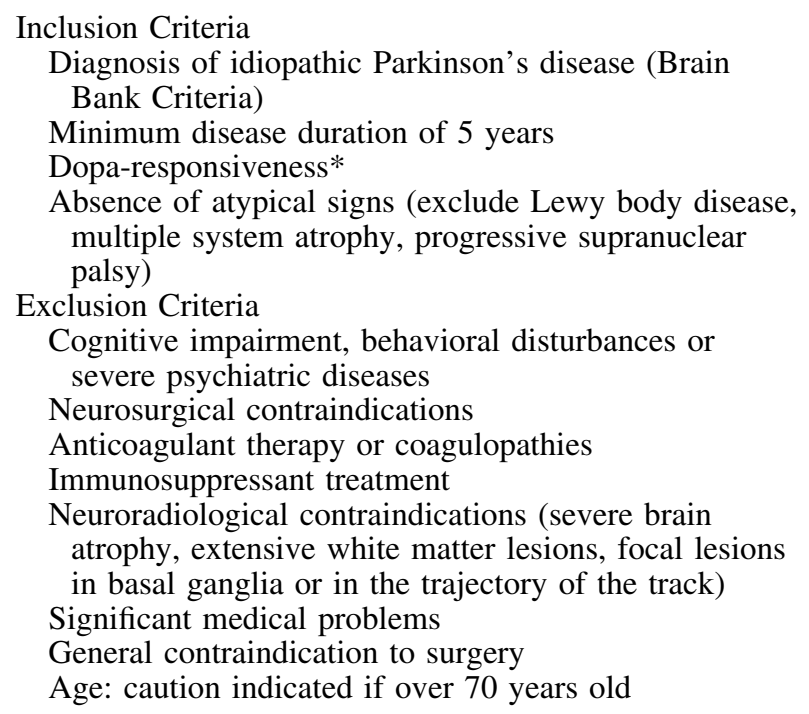

*Dopa responsiveness is defined as $>40 \%$ reduction in UPDRS motor scores after administration of an effective dose of levodopa, with respect to scores in the off-medication state. ${ }^{87}$

established and, although these patients can improve,$^{24,88-90}$ they are also at risk of worsening. ${ }^{91}$

No specific age cutoff has been defined for DBS. Decisions for or against DBS in the elderly population should be individualized, taking into account the grade of disability, risk factors for complications, general life expectancy, and the patient's motivation. Unilateral procedures could be an option in some of patients who are otherwise at too high a risk for a bilateral procedure. Thalamic and GPi DBS are usually considered a preferred choice in the older population.

Regarding disease duration, it is unknown which is the shortest duration for surgical consideration. A multicenter study is in progress to evaluate the effect of STN DBS earlier in the course of the disease. ${ }^{92}$ The potential and expected benefits of an earlier DBS approach should be to improve not only motor disability but also quality of life, by treating patients before personal, social, and professional degradation occurs.

The risk assessment involves an evaluation of the general condition of the patient (in particular, cardiovascular state), as well as a psychiatric history and cognitive function. Cognitive functions should be assessed in detail, to exclude patients with cognitive decline. A cranial MRI scan is usually performed, to exclude vascular disease, atrophy, or focal lesions. ${ }^{93}$ Speech and swallowing have to be assessed, because of the risk of deterioration after surgery. Antiaggregant, anticoagulant, and nonsteroidal anti-inflammatory treatment should be stopped for 2 weeks before and after surgery (Table 4).

Patients and their families should be given detailed information about the procedure, the risks, and the potential benefits as well as the limitations of any surgery. The patient's and the family's expectations must be fully addressed. The choice of target depends on the profile of symptoms and the risk factors. Table 5 lists criteria of selection more specific of each target. The criteria tend to be more selective for STN DBS.

\section{FUTURE OF DBS}

There is still some variability in the improvement observed in patients after DBS procedure, as well as side effects from surgery. Refinement in target localization, possibly with high-field MRI, and refinement in patient selection might assist. The development of a new generation of equipment with smaller batteries lasting longer will be beneficial. The possibility of using stimulators to deliver a different type of electrical signal is also under investigation, including the use of a device recording brain activity and then delivering adapted electrical pulses.

Although DBS can have a major effect on a range of symptoms, only a small group of parkinsonian patients are suitable for the existing procedures. Many very disabled patients are at too high risk. Patients with dementia or severe psychosis are at risks of these symptoms wors-

Table 5. Target Selection Criteria for Deep Brain Stimulation in Parkinson's Disease

\begin{tabular}{|c|c|c|c|}
\hline & STN & $\mathrm{GPi}$ & Vim \\
\hline PD features & $\begin{array}{l}\text { Medically intractable motor } \\
\text { fluctuations, dyskinesia, } \\
\text { or tremor. Major } \\
\text { disability from off- } \\
\text { symptoms. }\end{array}$ & $\begin{array}{l}\text { Medically intractable motor } \\
\text { fluctuations. Major disability } \\
\text { from dyskinesias. }\end{array}$ & $\begin{array}{l}\text { Medically intractable tremor. No major } \\
\text { disability from other parkinsonian } \\
\text { symptoms. High risk for STN. }\end{array}$ \\
\hline Concerns & $\begin{array}{l}\text { Dysarthria and dysphagia. } \\
\text { Balance and gait } \\
\text { problems non-dopa- } \\
\text { responsive. Psychiatric } \\
\text { problems. }\end{array}$ & $\begin{array}{l}\text { STN a concern because of age, } \\
\text { psychiatric history, or } \\
\text { cognition problems. }\end{array}$ & Speech and balance problems. \\
\hline
\end{tabular}

$\mathrm{GPi}=$ globus pallidus internus; $\mathrm{STN}=$ subthalamic nucleus; Vim $=$ ventral intermediate nucleus of the thalamus. 
ening. Other patients are unlikely to benefit from the existing surgical procedures, in particular patients with dopa-refractory freezing and balance problems. Another limitation of DBS is that, according to present knowledge, it has only a symptomatic effect and does not alter the progression of the disease. At 5 years after DBS, many features are not as good as after 1 year; in particular, axial symptoms such as gait, balance, and speech often deteriorate. A number of patients also develop dementia. There remains a need to identify new targets or different approaches to the treatment of Parkinson's disease.

In the case of dopa-refractory gait, there is hope that another target could be used. Preliminary results of DBS in the pedunculopontine nucleus (PPN) area have shown improvement of some aspects of gait in a few cases. ${ }^{94-96}$ The PPN differs from the other DBS targets, because an inactivation of this area would be expected to worsen the symptoms, whereas for all other targets both lesions and DBS have similar effects and the DBS is usually considered to have an inhibitory-like effect. For PPN DBS, lower frequency stimulation has been used, and this is likely to have an activation effect. The results are still preliminary, and many aspects are still debated, such as the exact position of the implanted electrodes. ${ }^{97,98} \mathrm{An}$ other limit of the existing data is the small number of patients and the lack of clinical details.

There is at present no real surgical alternative to DBS. Dopaminergic cell transplant and intraputaminal delivery of glial cell line-derived neurotrophic factor (GDNF) have shown some improvement in a small number of patients, but these procedures have been stopped because of side effects and lack of consistency in the effect in the present form..$^{99}$ Nevertheless, the principle of this treatment has been demonstrated, that it can work in some patients, and this might lead to other approaches based on the same principles. Other forms of restorative treatment are being investigated, in particular gene therapy. ${ }^{100}$ Those approaches might in the future replace DBS for many patients.

Acknowledgments: This work was undertaken at University College London Hospitals and University College London (UCLH/UCL) with a proportion of funding from the Department of Health's National Institute for Health Research (NIHR) Biomedical Research Centres funding scheme. The Unit of Functional Neurosurgery is supported by the Parkinson's Appeal. I.M.T. is supported by a fellowship of the European Federation of Neurological Societies and the Rosetrees Trust.

\section{REFERENCES}

1. Sem-Jacobsen CW. Depth electrographic stimulation and treatment of patients with Parkinson's disease including neurosurgical technique. Acta Neurol Scand 1965;13:365-377.

2. Bechtereva NP, Bondarchuk AN, Smirnov VM, Meliucheva LA. Therapeutic electric stimulation of deep brain structures [In Russian]. Vopr Neirokhir 1972;36:7-12.

3. Benabid AL, Pollak P, Louveau A, Henry S, de Rougemont J. Combined (thalamotomy and stimulation) stereotactic surgery of the VIM thalamic nucleus for bilateral Parkinson disease. Appl Neurophysiol 1987;50:344-346.

4. Benabid AL, Pollak P, Gervason C, et al. Long-term suppression of tremor by chronic stimulation of the ventral intermediate thalamic nucleus. Lancet 1991;337:403-406.

5. Pollak P, Benabid AL, Gross C, et al. Effects of the stimulation of the subthalamic nucleus in Parkinson disease [In French]. Rev Neurol (Paris) 1993;149:175-176.

6. Limousin P, Pollak P, Benazzouz A, et al. Effect on parkinsonian signs and symptoms of bilateral subthalamic nucleus stimulation. Lancet 1995;345:91-95.

7. Siegfried J, Lippitz B. Bilateral chronic electrostimulation of ventroposterolateral pallidum: a new therapeutic approach for alleviating all parkinsonian symptoms. Neurosurgery 1994;35: $1126-1130$.

8. Laitinen LV, Bergenheim AT, Hariz MI. Leksell's posteroventral pallidotomy in the treatment of Parkinson's disease. J Neurosurg 1992;76:53-61.

9. Bergman H, Wichmann T, DeLong MR. Reversal of experimental parkinsonism by lesions of the subthalamic nucleus. Science 1990;249:1436-1438.

10. Aziz TZ, Peggs D, Agarwal E, Sambrook MA, Crossman AR. Subthalamic nucleotomy alleviates parkinsonism in the 1-methyl4-phenyl-1,2,3,6-tetrahydropyridine (MPTP)-exposed primate. Br J Neurosurg 1992;6:575-582.

11. Benazzouz A, Gross C, Féger J, Boraud T, Bioulac B. Reversal of rigidity and improvement in motor performance by subthalamic high-frequency stimulation in MPTP-treated monkeys. Eur J Neurosci 1993;5:382-389.

12. Maltête D, Navarro S, Welter ML, et al. Subthalamic stimulation in Parkinson disease: with or without anesthesia? Arch Neurol 2004;61:390-392.

13. Hariz MI, Krack P, Melvill R, et al. A quick and universal method for stereotactic visualization of the subthalamic nucleus before and after implantation of deep brain stimulation electrodes. Stereotact Funct Neurosurg 2003;80:96-101.

14. Garonzik IM, Hua SE, Ohara S, Lenz F. Intraoperative microelectrode and semi-microelectrode recording during the physiological localization of the thalamic nucleus ventral intermediate. Mov Disord 2002;17 Suppl 3:S135-S144.

15. Hutchison WD, Allan RJ, Opitz H, et al. Neurophysiological identification of the subthalamic nucleus in surgery for Parkinson's disease. Ann Neurol 1998;44:622-628.

16. Hariz MI. Safety and risk of microelectrode recording in surgery for movement disorders. Stereotact Funct Neurosurg 2002;78: $146-157$.

17. Chen CC, Pogosyan A, Zrinzo L, et al. Intra-operative recordings of local field potentials can help localize the subthalamic nucleus in Parkinson's disease surgery. Exp Neurol 2006;198:214-221.

18. Volkmann J, Sturm V, Weiss P, et al. Bilateral high-frequency stimulation of the internal globus pallidus in advanced Parkinson's disease. Ann Neurol 1998;44:953-961.

19. Kumar R, Lang AE, Rodriguez-Oroz MC, et al. Deep brain stimulation of the globus pallidus pars interna in advanced Parkinson's disease. Neurology 2000;55 Suppl 6:S34-S39.

20. Lyons KE, Wilkinson S, Tröster AI, Pahwa R. Long-term efficacy of globus pallidus stimulation for the treatment of Parkinson's disease. Sterotact Funct Neurosurg 2002;79:214-220.

21. Loher TJ, Burgunder JM, Pohle T, Weber S, Sommerhalder R, Krauss JK. Long-term pallidal deep brain stimulation in patients with advanced Parkinson disease: 1-year follow-up study. J Neurosurg 2002;96:844-853.

22. Krack P, Batir A, Van Blercom N, et al. Five-year follow-up of bilateral stimulation of the subthalamic nucleus in advanced Parkinson's disease. N Engl J Med 2003;349:1925-1934.

23. Herzog J, Volkmann J, Krack P, et al. Two-year follow-up of subthalamic deep brain stimulation in Parkinson's disease. Mov Disord 2003;18:1332-1337.

24. Volkmann J, Allert N, Voges J, Sturm V, Schnitzler A, Freund HJ. Long-term results of bilateral pallidal stimulation in Parkinson's disease. Ann Neurol 2004;55:871-875. 
25. Krause M, Fogel W, Mayer P, Kloss M, Tronnier V. Chronic inhibition of the subthalamic nucleus in Parkinson's disease. J Neurol Sci 2004;219:119-124.

26. Schüpbach WMM, Chastan N, Welter ML, et al. Stimulation of the subthalamic nucleus in Parkinson's disease: a 5 year follow up. J Neurol Neurosurg Psychiatry 2005;76:1640-1644.

27. Østergaard K, Sunde NA. Evolution of Parkinson's disease during 4 years of bilateral deep brain stimulation of the subthalamic nucleus. Mov Disord 2006;21:624-631.

28. Wider C, Pollo C, Bloch J, Burkhard PR, Vingerhoets FJG. Long-term outcome of 50 consecutive Parkinson's disease patients treated with subthalamic nucleus deep brain stimulation. Parkinsonism Relat Disord 2007 September 5 [Epub ahead of print].

29. Blomstedt P, Hariz MI. Hardware-related complications of deep brain stimulation: a ten year experience. Acta Neurochir (Wien) 2005;147:1061-1064.

30. Koller W, Pahwa R, Busenbark K, et al. High-frequency unilateral thalamic stimulation in the treatment of essential and parkinsonian tremor. Ann Neurol 1997;42:292-299.

31. Tasker RR. Deep brain stimulation is preferable to thalamotomy for tremor suppression. Surg Neurol 1998;49:145-153.

32. Limousin P, Speelman JD, Gielen F, Janssens M. Multicentre European study of thalamic stimulation in parkinsonian and essential tremor. J Neurol Neurosurg Psychiatry 1999;66:289-296.

33. Rehncrona S, Johnels B, Widner H, Törnqvist AL, Hariz M, Sydow O. Long-term efficacy of thalamic deep brain stimulation for tremor: double-blind assessments. Mov Disord 2003;18:163170 .

34. Hariz GM, Bergenheim AT, Hariz MI, Lindberg M. Assessment of ability/disability in patients treated with chronic thalamic stimulation for tremor. Mov Disord 1998;13:78-83.

35. Pollak P, Fraix V, Krack P, et al. Treatment results: Parkinson's disease. Mov Disord 2002;17 Suppl 3:S75-S83.

36. Defebvre L, Blatt JL, Blond S, Bourriez JL, Gieu JD, Destée A. Effect of thalamic stimulation on gait in Parkinson disease. Arch Neurol 1996;53:898-903.

37. Woods SP, Fields JA, Lyons KE, et al. Neuropsychological and quality of life changes following unilateral thalamic deep brain stimulation in Parkinson's disease: a one-year follow-up. Acta Neurochir 2001;143:1273-1277.

38. Hariz MI, Krack P, Alesch F, et al. Multicentre European study of thalamic stimulation for parkinsonian tremor: a 6-year follow-up. J Neurol Neurosurg Psychiatry 2007 Sep 26 [Epub ahead of print].

39. Krack P, Pollak P, Limousin P, Benazzouz A, Benabid AL. Stimulation of subthalamic nucleus alleviates tremor in Parkinson's disease. Lancet 1997;350:1675.

40. Fraix V, Pollak P, Moro E, et al. Subthalamic nucleus stimulation in tremor dominant parkinsonian patients with previous thalamic surgery. J Neurol Neurosurg Psychiatry 2005;76:246-248.

41. Caparros-Lefebvre D, Blond S, Pécheux N, Pasquier F, Petit H. Neuropsychological evaluation before and after thalamic stimulation in 9 patients with Parkinson's disease [In French]. Rev Neurol (Paris) 1992;148:117-122.

42. Schuurman PR, Bruins J, Merkus MP, Bosch DA, Speelman JD. A comparison of neuropsychological effects of thalamotomy and thalamic stimulation. Neurology 2002;59:1232-1239.

43. Hariz MI, Shamsgovara P, Johansson F, Hariz G, Fodstad H. Tolerance and tremor rebound following long-term chronic thalamic stimulation for parkinsonian and essential tremor. Stereotact Funct Neurosurg 1999;72:208-218.

44. Ghika J, Villemure JG, Fankhauser H, Favre J, Assal G, GhikaSchmid F. Efficiency and safety of bilateral contemporaneous pallidal stimulation (deep brain stimulation) in levodopa-responsive patients with Parkinson's disease with severe motor fluctuations: a 2-year follow-up review. J Neurosurg 1998;89:713-718.

45. Durif F, Lemaire JJ, Debilly B, Dordain G. Long-term follow-up of globus pallidus chronic stimulation in advanced Parkinson's disease. Mov Disord 2002;17:803-807.

46. Deep Brain Stimulation for Parkinson's Disease Study Group. Deep-brain stimulation of the subthalamic nucleus or the pars interna of the globus pallidus in Parkinson's disease. N Engl J Med 2001;345:956-963.

47. Rodriguez-Oroz MC, Obeso JA, Lang AE, et al. Bilateral deep brain stimulation in Parkinson's disease: a multicentre study with 4 years follow-up. Brain 2005;128:2240-2249.

48. Rodrigues JP, Walters SE, Watson P, Stell R, Mastaglia FL. Globus pallidus stimulation in advanced Parkinson's disease. J Clin Neurosci 2007;14:208-215.

49. Krack P, Pollak P, Limousin P, et al. Opposite motor effects of pallidal stimulation in Parkinson's disease. Ann Neurol 1998;43: 180-192.

50. Bejjani B, Damier P, Arnulf I, et al. Pallidal stimulation for Parkinson's disease: two targets? Neurology 1997;49:15641569.

51. Rodrigues JP, Walters SE, Watson P, Stell R, Mastaglia FL. Globus pallidus stimulation improves both motor and nonmotor aspects of quality of life in advanced Parkinson's disease. Mov Disord 2007;22:1866-1870.

52. Anderson VC, Burchiel KJ, Hogarth P, Favre J, Hammerstad J. Pallidal vs subthalamic nucleus deep brain stimulation in Parkinson's disease. Arch Neurol 2005;62:554-560.

53. Volkmann J, Allert N, Voges J, Weiss PH, Freund HJ, Sturm V. Safety and efficacy of pallidal or subthalamic nucleus stimulation in advanced PD [Erratum in: Neurology 2001;57:1354]. Neurology 2001;56:548-551.

54. Limousin P, Krack P, Pollak P, et al. Electrical stimulation of the subthalamic nucleus in advanced Parkinson's disease. N Engl J Med 1998;339:1105-1111.

55. Rodriguez-Oroz MC, Zamarbide I, Guridi J, Palmero MR, Obeso JA. Efficacy of deep brain stimulation of the subthalamic nucleus in Parkinson's disease 4 years after surgery: double blind and open label evaluation. J Neurol Neursurg Psychiatry 2004;75: 1382-1385.

56. Deuschl G, Schade-Brittinger C, Krack P, et al. A Randomized trial of deep brain stimulation for Parkinson's disease [Erratum in: N Engl J Med 2006;355:1289]. N Engl J Med 2006;355:896908.

57. Kleiner-Fisman G, Fisman D, Sime E, Saint-Cyr JA, Lozano A, Lang A. Long-term follow up of bilateral deep brain stimulation of the subthalamic nucleus in patients with advanced Parkinson disease. J Neurosurg 2003;99:489-495.

58. Krack P, Pollak P, Limousin P, Benazzouz A, Deuschl G, Benabid AL. From off-period dystonia to peak-dose chorea: the clinical spectrum of varying subthalamic nucleus activity. Brain 1999;122:1133-1146.

59. Klostermann F, Ehlen F, Vesper J, et al. Effects of subthalamic deep brain stimulation on dysarthrophonia in Parkinson's disease. J Neurol Neurosurg Psychiatry 2007 Aug 31 [Epub ahead of print].

60. Funkiewiez A, Ardouin C, Caputo E, et al. Long term effects of bilateral subthalamic nucleus stimulation on cognitive function, mood, and behaviour in Parkinson's disease. J Neurol Neurosurg Psychiatry 2004; 75:834-839.

61. Aybek S, Gronchi-Perrin A, Berney A, et al. Long-term cognitive profile and incidence of dementia after STN-DBS in Parkinson's disease. Mov Disord 2007;22:974-981.

62. Wallace BA, Ashkan K, Heise CE, et al. Survival of midbrain dopaminergic cells after lesion or deep brain stimulation of the subthalamic nucleus in MPTP-treated monkeys. Brain 2007;130: 2129-2145.

63. Lagrange E, Krack P, Moro E, et al. Bilateral subthalamic nucleus stimulation improves health-related quality of life in PD. Neurology 2002;59:1976-1978.

64. Lezcano E, Gómez-Esteban JC, Zarranz JJ, et al. Improvement in quality of life in patients with advanced Parkinson's disease following bilateral deep-brain stimulation in subthalamic nucleus. Eur J Neurol 2004;11:451-454.

65. Lyons KE, Pahwa R. Long-term benefits in quality of life provided by bilateral subthalamic stimulation in patients with Parkinson disease. J Neurosurg 2005;103:252-255.

66. Drapier S, Raoul S, Drapier D, et al. Only physical aspects of quality of life are significantly improved by bilateral subthalamic stimulation in Parkinson's disease. J Neurol 2005;252:583-588. 
67. Martínez-Martín P, Valldeoriola F, Tolosa E, et al. Bilateral subthalamic nucleus stimulation and quality of life in advanced Parkinson's disease. Mov Disord 2002;17:372-377.

68. Derost PP, Ouschchane I, Morand D, et al. Is DBS-STN appropriate to treat severe Parkinson's disease in an elderly population? Neurology 2007;68:1345-1355.

69. Ory-Magne F, Brefel-Courbon C, Simonetta-Moreau M. Does ageing influence deep brain stimulation outcomes in Parkinson's disease? Mov Disord 2007;22:1457-1463.

70. Schüpbach M, Gargiulo M, Welter ML, et al. Neurosurgery in Parkinson disease: a distressed mind in a repaired body? Neurology 2006;66:1811-1816.

71. Zibetti M, Torre E, Cinquepalmi A, et al. Motor and nonmotor symptom follow-up in parkinsonian patients after deep brain stimulation of the subthalamic nucleus. Eur Neurol 2007;58:218223.

72. Cicolin A, Lopiano L, Zibetti, et al. Effects of deep brain stimulation of the subthalamic nucleus on sleep architecture in parkinsonian patients. Sleep Med 2004;5:207-210.

73. Witjas T, Kaphan E, Regis J, et al. Effects of chronic subthalamic stimulation on nonmotor fluctuations in Parkinson's disease. Mov Disord 2007;22:1729-1734.

74. Winge K, Nielsen KK, Stimpel H, Lokkegaard A, Jensen SR, Werdelin L. Lower urinary tract symptoms and bladder control in advanced Parkinson's disease: effects of deep brain stimulation in the subthalamic nucleus. Mov Disord 2007;22:220-225.

75. Seif C, Herzog J, Van der Horst C, et al. Effect of subthalamic deep brain stimulation on the function of the urinary bladder. Ann Neurol 2004;55:118-120.

76. Fraix V, Houeto JL, Lagrange C, et al.; SPARK Study Group. Clinical and economic results of bilateral subthalamic nucleus stimulation in Parkinson's disease. J Neurol Neurosurg Psychiatry 2006;77:443-449.

77. Valldeoriola F, Morsi O, Tolosa E, Rumià J, Martí MJ, MartínezMartín P. Prospective comparative study on cost-effectiveness of subthalamic stimulation and best medical treatment in advanced Parkinson's disease. Mov Disord 2007;22:2183-2191.

78. Mandat TS, Hurwitz T, Honey CR. Hypomania as an adverse effect of subthalamic nucleus stimulation: report of two cases. Acta Neurochir (Wien) 2006;148:895-897.

79. Bordini BJ, Grag A, Gallagher CL, Bell B, Garell PC. Neuropsychological effects of bilateral deep brain stimulation of the subthalamic nucleus in Parkinson's disease. Stereotact Funct Neurosurg 2007;85:113-120.

80. Contarino MF, Daniele A, Sibilia AH, et al. cognitive outcome 5 years after bilateral chronic stimulation of subthalamic nucleus in patients with Parkinson's disease. J Neurol Neurosurg Psychiatry 2007;78:248-252.

81. Parson TD, Rogers SA, Braaten AJ, Woods SP, Tröster AI. Cognitive sequelae of subthalamic nucleus deep brain stimulation in Parkinson's disease: a meta-analysis. Lancet Neurol 2006;5: $578-588$.

82. Hariz MI, Johansson F, Shamsgovara P, Johansson E, Hariz GM, Fagerlund M. Bilateral subthalamic nucleus stimulation in a parkinsonian patient with preoperative deficits in speech and cognition: persistent improvement in mobility but increased dependency: a case study. Mov Disord 2000;15:136-139.
83. Peppe A, Pierantozzi M, Bassi A, et al. Stimulation of the subthalamic nucleus compared with the globus pallidus internus in patients with Parkinson disease. J Neurosurg 2004;101:195-200.

84. Krause M, Fogel W, Heck A, et al. Deep brain stimulation for the treatment of Parkinson's disease: subthalamic nucleus versus globus pallidus internus. J Neurol Neurosurg Psychiatry 2001;70: 464-470.

85. Krack P, Pollak P, Limousin P, et al. Subthalamic nucleus or internal pallidal stimulation in young onset Parkinson's disease. Brain 1998;121:451-457.

86. Esselink RA. de Bie RM, de Haan RJ, et al. Unilateral pallidotomy versus bilateral subthalamic nucleus stimulation in PD: a randomized trial. Neurology 2004;62:201-207.

87. Welter ML, Houeto JL, Tezenas du Montcel S, et al. Clinical predictive factors of subthalamic stimulation in Parkinson's disease. Brain 2002;125:575-583.

88. Witjas T, Baunez C, Henry JM, et al. Addiction in Parkinson's disease: impact of subthalamic nucleus deep brain stimulation. Mov Disord 2005;20:1052-1055.

89. Bandini F, Primavera A, Pizzorno M, Cocito L. Using STN DBS and medication reduction as a strategy to treat pathological gambling in Parkinson's disease. Parkinsonism Relat Disord 2007;13: 369-371.

90. Ardouin C, Voon V, Worbe Y, et al. Pathological gambling in Parkinson's disease improves on chronic subthalamic nucleus stimulation. Mov Disord 2006:21:1941-1946.

91. Houeto JL, Mesnage V, Mallet L, et al. Behavioural disorders, Parkinson's disease and subthalamic stimulation. J Neurol Neurosurg Psychiatry 2002;72:701-707.

92. Schüpbach WM, Maltête D, Houeto JL. Neurosurgery at an earlier stage of Parkinson's disease: a randomized, controlled trial. Neurology 2007;68:267-271.

93. Defer G-L, Widner H, Marié RM, Rémy P, Levivier M. Core Assessment Program for Surgical Interventional Therapies in Parkinson's Disease (CAPSIT-PD). Mov Disord 1999;14:572-584.

94. Plaha P, Gill SS. Bilateral deep brain stimulation of the pedunculopontine nucleus for Parkinson's disease. Neuroreport 2005; 16:1883-1887.

95. Mazzone P, Lozano A, Stanzione P, et al. Implantation of human pedunculopontine nucleus: a safe and clinically relevant target in Parkinson's disease. Neuroreport 2005;16:1877-1881.

96. Stefani A, Lozano AM, Peppe A, et al. Bilateral deep brain stimulation of the pedunculopontine and subthalamic nuclei in severe Parkinson's disease. Brain 2007;130:1595-1607.

97. Zrinzo L, Zrinzo LV, Hariz M. the pedunculopontine and peripeduncular nuclei: a tale of two structures. Brain 2007;130:e73.

98. Yelnik J. PPN or PPD, what is the target for deep brain stimulation in Parkinson's disease? Brain 2007;130:e79.

99. Gill SS, Patel NK, Hotton GR, et al. Direct brain infusion of glial cell line-derived neurotrophic factor in Parkinson disease. Nat Med 2003;9:589-595.

100. Kaplitt MG, Feigin A, Tang C, et al. Safety and tolerability of gene therapy with an adeno-associated virus (AAV) borne GAD gene for Parkinson's disease: an open label, phase I trial. Lancet 2007;369:2097-2105. 